\title{
Age- and weight group-specific weight gain patterns in children and adolescents during the 15 years before and during the COVID-19 pandemic.
}

Mandy Vogel ( $\square$ mandy.vogel@medizin.uni-leipzig.de)

Leipzig University https://orcid.org/0000-0003-2051-1249

Mandy Geserick

Leipzig University

Ruth Gausche

Leipzig University

Christoph Beger

Leipzig University

Tanja Poulain

Leipzig University

Christof Meigen

Leipzig University

Antje Körner

Center for Pediatric Research Leipzig (CPL), University Hospital for Children \& Adolescents, University of Leipzig, Leipzig https://orcid.org/0000-0001-6001-0356

Anne Jurkutat

Leipzig University

Eberhard Keller

Leipzig University

Roland Pfäffle

Leipzig University

Article

Keywords: COVID-19, children, Body mass index, obesity, overweight, pandemic

Posted Date: June 24th, 2021

DOI: https://doi.org/10.21203/rs.3.rs-255574/v1

License: (a) (i) This work is licensed under a Creative Commons Attribution 4.0 International License.

Read Full License 
Version of Record: A version of this preprint was published at International Journal of Obesity on September 23rd, 2021. See the published version at https://doi.org/10.1038/s41366-021-00968-2. 


\section{Abstract}

Background/Objectives: There is concern that measures aiming to limit a further spread of COVID-19, e.g., school closures and social distancing, cause an aggravation of the childhood obesity epidemic. Therefore, we aimed to compare BMI trends during the 15 years before and during the COVID-19 pandemic.

Subjects/Methods: To assess the change in weight dynamics during the first months of COVID-19, we compared the trends of $\mathrm{BMI}$ change $(\triangle \mathrm{BMI}-\mathrm{SDS})$ and of the proportions of children gaining or losing weight between 2005 and 2019 and the respective changes from 2019 (pre-pandemic) to 2020 (after the onset of anti-pandemic measures) in more than 150000 children.

Results: During the COVID-19 pandemic, we found a substantial weight gain across all weight and age groups, reflected by an increase in mean BMI-SDS ( $\beta=0.05,95 \% \mathrm{Cl} 0.036$ to $0.055 ; p<0.001)$, an increase in the proportion of children gaining weight $(\mathrm{OR}=1.37,95 \% \mathrm{Cl} 1.28$ to $1.46 ; \mathrm{p}<0.001)$, and a decrease in the proportion of children losing weight $(\mathrm{OR}=0.72,95 \% \mathrm{Cl} 0.67$ to $0.77 ; \mathrm{p}<0.001)$. Besides, we found the same trends since 2005 on a low but stable level with a mean $\triangle B M I-S D S$ increase of $\beta=0.007(95 \% \mathrm{Cl}$ 0.006 to $0.009 ; p<0.001)$ every five years, the odds of gaining weight increased by $\mathrm{OR}=1.05(95 \% \mathrm{Cl} 1.03$ to $1.06 ; p<0.001)$ per five years, and the odds of losing weight decreased by $\mathrm{OR}=0.95(95 \% \mathrm{Cl} 0.94$ to $0.96 ; p<0.001)$ per five years. Alarmingly, both the long-term and the short-term effects were most pronounced in the obese subgroup.

Conclusions: There are positive dynamics in different measures of weight change, indicating a positive trend in weight gain patterns, especially within the group of obese children. These dynamics are likely to be escalated by the COVID-19-related measures and may lead to a significant further aggravation of the childhood obesity pandemic.

\section{Introduction}

On March 11, 2020, the World Health Organization termed the COVID-19 outbreak a pandemic. Many countries have been affected and took measures to limit infection rates. Those measures included social distancing, home confinement, the closure of shops, sports and cultural facilities, and schools and nurseries. Children, although only mildly affected by the virus itself, experienced profound disruption of their daily lives. Besides adverse psychological effects like increased anxiety and loneliness, ${ }^{1,2}$ different scientists worry about an increase in overweight and obesity caused by a decline in physical activity (PA), an increase in sedentary behavior (SB), and a change in dietary behavior ${ }^{3,4}$ associated with increased snacking ${ }^{5}$ or higher consumption of ultra-processed food. ${ }^{6}$ Indeed, several studies showed a decrease in PA accompanied by an increase in SB in children during the COVID-19-induced confinement. ${ }^{5-8}$ Although studies indicated a lockdown-related weight gain in adults, ${ }^{9,10}$ to our knowledge, there is no study examining the consequences of the COVID-19-induced behavioral changes on the weight status in a large population-based cohort of children and adolescents. However, the monitoring of children's weight status 
is of particular interest because childhood obesity is likely to persist into adulthood. ${ }^{11}$ With 158000000 affected children, childhood obesity is a pandemic on its own. ${ }^{12}$ It is related to many comorbidities like hypertension, impaired glucose metabolism, and even cancer ${ }^{13}$ or depression; ${ }^{14}$ an earlier onset is often related to more severe sequelae. ${ }^{14}$ Moreover, in the context of COVID-19, obesity increases the likelihood of severe disease progression, even in children. ${ }^{13,15}$

Based on the weight trend pattern during school time and summer recess, a simulation study predicted an increase of the mean BMI-SDS during COVID-19-induced school closures. ${ }^{16}$ Other studies showed associations between an increase in overweight/obesity prevalences and economic crises ${ }^{17,18}$ or natural disasters. ${ }^{19}$ With more than 500000000 children affected by the COVID-19-induced measures, ${ }^{20}$ even small effects can cause a tremendous aggravation of the childhood obesity pandemic. Therefore, our study compared the trends of BMl changes and proportions of high positive/negative weight changes from 2005 to 2019 with the respective changes from 2019 (pre-pandemic) to 2020 (after the onset of anti-pandemic measures) in a large pediatric cohort in Germany.

\section{Subjects And Methods}

\section{Participants and Setting}

Data were retrieved from the CrescNet patient registry, a network of primary care pediatricians, endocrinological treatment centers, and clinics in Germany. It aims to monitor children's growth and development for clinical and scientific purposes. ${ }^{21}$ Height and weight were measured at each visit by trained staff according to standardized procedures. Data on age, sex, height, weight, and diagnoses from any consultation are pseudonymized and transferred to the CrescNet registry. The registry was approved by the Federal Saxonian Data Protection Authority and is registered at ClinicalTrials.gov (NCT03072537). All healthy children aged $\geq$ one year with a height and weight measurement between September 2019 and February 2020 (t0) and a follow-up measurement between April and July 2020 (t1) were selected from the CrescNet database; the same selection process was done for the years 2005-2019. If children had more than one eligible pair of measurements per year, only the last one was used for analyses. Children with health conditions affecting weight or body composition were not selected. The list of excluded diagnoses is included in Supplementary Table 1 in the Online-Only Supplements.

\section{Measures}

According to the current German guidelines, ${ }^{22} \mathrm{BMI}$ was calculated and transformed to standard deviation scores (BMI-SDS) using the references by Kromeyer-Hauschild ${ }^{23}$. For each year, the change of BMI-SDS between t0 and 11 was calculated as the standardized difference per 3-months ( $\triangle \mathrm{BMI}-\mathrm{SDS})$. Three monthly change rates were chosen because it corresponds to the duration of the first lockdown period in Germany. Classification into the following weight groups was based on BMI-SDS at t0: underweight (UW, $<-1.28$ BMI-SDS), normal weight (NW, $-1.28 \leq$ BMI-SDS $<1.28$ ), overweight $(\mathrm{OW}, 1.28 \leq \mathrm{BMI}-\mathrm{SDS}<1.88$ ), and obese $\left(\mathrm{OB}, \mathrm{BMI}-\mathrm{SDS} \geq 1.88\right.$ ) also according to the German guidelines. ${ }^{22}$ Age at to was used to define 
three age groups: 1-6 years (nursery, preschool), 6-12 (primary school), and 12-18 (secondary school). According to Geserick et al., a change outside \pm 0.2 BMI-SDS per year was classified as a high positive or a high negative change, respectively. ${ }^{11}$

\section{Statistical Methods}

Descriptive statistics were given as mean (standard deviation) for continuous variables and counts (percentage) for categorical variables. To model the time trend of $\triangle B M I-S D S$, generalized additive mixed models (GAMM) were applied with $\triangle \mathrm{BMI}$-SDS as outcome and the numeric equivalent of $\mathrm{t} 1$ (centered around 2010 for numerical reasons) as independent variable stratified by weight/age group. Cubic splines were used as smoothing terms. Accordingly, time trends of the proportions of high positive/negative change were estimated applying logistic GAMM. Subsequently, because for all age and weight groups the $\triangle \mathrm{BMI}-\mathrm{SDS}$ and the proportions of high positive/negative change were relatively stable between 2005 and 2019 (Figs. 1 and 2), effects for the respective trends from 2015 to 2019 were estimated using (logistic) linear mixed regression models as was the change between 2019 and 2020. Results are presented as change/odds ratio (OR) per 5 years for the trends between 2005 and 2019 and as change/OR from 2019 to 2020 , including the $95 \%$ confidence interval $(95 \% \mathrm{Cl})$. Differences in trends between a) weight groups, b) age groups, and c) boys and girls were examined. To adjust results for multiple measurements per subject, we included the respective random effects in the models. The confidence level was set to $a=0.05$. P-values and confidence intervals were adjusted for multiple testing using a method controlling for family-wise error rates as described in Hothorn et al. ${ }^{24}$ All hypothesis tests were 2-sided. All statistical analyses were performed using R, v.4.0. ${ }^{25}$

\section{Results}

Data from 268375 children were retrieved from the CrescNet registry. We excluded 87 measurements from 23 children because of an extreme BMI-SDS (outside the interval $[-5,5]$ ) and 166 measurements from 45 children because they had an extreme change rate ( $\triangle \mathrm{BMI}$-SDS $>2$ for children aged $\geq 3$ or $\triangle \mathrm{BMI}$-SDS $>$ 3 for children aged $<3$ years because smaller children have higher natural variability in BMI-SDS). We considered those extreme values to be likely due to severe organic disorders. Finally, 246375 measurement pairs from 150152 children were included in the analyses. The numbers of children included per year, weight, and age group are given in Supplementary Table 2 in the Online-Only Supplements. Basic descriptive statistics by year are given in Table 1. Interestingly, $\triangle B M I-S D S$ trends differed between age and weight groups but not between sexes (Supplementary Fig. 1 in the Online-Only Supplements). The same was true for percentages of high positive and high negative changes (Supplementary Figs. 2 and 3 in the Online-Only Supplements). Therefore, sex was not considered during further analyses. In general, the trends differed more between weight groups than between age groups (Figs. 1 and 2). We found no significant interaction between age and weight group. 
Table 1

Characteristics of the study population stratified by year.

\begin{tabular}{|c|c|c|c|c|c|c|c|c|}
\hline & 2005 & 2006 & 2007 & 2008 & 2009 & 2010 & 2011 & 2012 \\
\hline & $\begin{array}{l}N= \\
17871\end{array}$ & $\begin{array}{l}N= \\
16757\end{array}$ & $\begin{array}{l}N= \\
16478\end{array}$ & $\begin{array}{l}N= \\
18269\end{array}$ & $\begin{array}{l}N= \\
18136\end{array}$ & $\begin{array}{l}N= \\
16956\end{array}$ & $\begin{array}{l}N= \\
16716\end{array}$ & $\begin{array}{l}N= \\
16471\end{array}$ \\
\hline \multicolumn{9}{|l|}{ Sex: } \\
\hline \multirow[t]{2}{*}{ male } & 9153 & 8603 & 8407 & 9392 & 9609 & 8935 & 8794 & 8744 \\
\hline & $(51 \%)$ & $(51 \%)$ & $(51 \%)$ & $(51 \%)$ & $(53 \%)$ & $(53 \%)$ & $(53 \%)$ & $(53 \%)$ \\
\hline \multirow[t]{2}{*}{ female } & 8718 & 8154 & 8071 & 8877 & 8527 & 8021 & 7922 & 7727 \\
\hline & (49\%) & $(49 \%)$ & $(49 \%)$ & $(49 \%)$ & (47\%) & $(47 \%)$ & (47\%) & $(47 \%)$ \\
\hline \multirow{2}{*}{$\begin{array}{l}\text { Age t0 } \\
\text { (years) }\end{array}$} & 6.89 & 6.70 & 6.77 & 6.79 & 6.72 & 6.87( & 6.91 & 6.86 \\
\hline & $(4.41)$ & $(4.31)$ & $(4.41)$ & $(4.31)$ & $(4.35)$ & 4.37) & (4.39) & $(4.43)$ \\
\hline \multirow[t]{2}{*}{$\Delta$ Age (years) } & 0.50 & 0.50 & 0.50 & 0.48 & 0.48 & 0.48 & 0.48 & 0.49 \\
\hline & $(0.16)$ & $(0.16)$ & $(0.16)$ & $(0.16)$ & $(0.17)$ & $(0.17)$ & $(0.16)$ & $(0.16)$ \\
\hline \multicolumn{9}{|l|}{$\begin{array}{l}\text { Weight group } \\
\text { (t0): }\end{array}$} \\
\hline \multirow[t]{2}{*}{ underweight } & 1465 & 1321 & 1423 & 1653 & 1715 & 1656 & 1635 & 1622 \\
\hline & $(8 \%)$ & $(8 \%)$ & $(9 \%)$ & (9\%) & $(9 \%)$ & $(10 \%)$ & $(10 \%)$ & $(10 \%)$ \\
\hline \multirow[t]{2}{*}{ normalweight } & 13528 & 12819 & 12491 & 13743 & 13534 & 12484 & 12321 & 11974 \\
\hline & & $(77 \%)$ & & & & & & \\
\hline \multirow[t]{2}{*}{ overweight } & 1643 & 1440 & 1397 & 1585 & 1595 & 1509 & 1456 & 1492 \\
\hline & $(9 \%)$ & $(9 \%)$ & $(8 \%)$ & $(9 \%)$ & (9\%) & (9\%) & (9\%) & (9\%) \\
\hline \multirow[t]{2}{*}{ obese } & 1235 & 1177 & 1167 & 1288 & 1292 & 1307 & 1304 & 1383 \\
\hline & $(7 \%)$ & $(7 \%)$ & $(7 \%)$ & $(7 \%)$ & $(7 \%)$ & $(8 \%)$ & $(8 \%)$ & $(8 \%)$ \\
\hline \multirow[t]{2}{*}{ BMI-SDS t0 } & 0.19 & 0.18 & 0.18 & 0.17 & 0.15 & 0.17 & 0.16 & 0.19 \\
\hline & (1.11) & $(1.09)$ & $(1.11)$ & (1.12) & $(1.14)$ & $(1.15)$ & $(1.16)$ & (1.16) \\
\hline \multirow[t]{2}{*}{ BMI-SDS t1 } & 0.17 & 0.15 & 0.15 & 0.15 & 0.16 & 0.17 & 0.17 & 0.19 \\
\hline & (1.10) & $(1.10)$ & $(1.11)$ & (1.11) & $(1.12)$ & $(1.14)$ & $(1.14)$ & (1.16) \\
\hline \multirow{3}{*}{$\begin{array}{l}\triangle \mathrm{BMI}-\mathrm{SDS} / 3 \\
\text { months }\end{array}$} & 0.00 & -0.02 & -0.01 & 0.00 & 0.01 & 0.01 & 0.01 & 0.01 \\
\hline & $(0.27)$ & $(0.27)$ & $(0.27)$ & $(0.28)$ & $(0.29)$ & $(0.29)$ & $(0.29)$ & $(0.28)$ \\
\hline & 2013 & 2014 & 2015 & 2016 & 2017 & 2018 & 2019 & 2020 \\
\hline
\end{tabular}




\begin{tabular}{|c|c|c|c|c|c|c|c|c|}
\hline & 2005 & 2006 & 2007 & 2008 & 2009 & 2010 & 2011 & 2012 \\
\hline & $\begin{array}{l}N= \\
13954\end{array}$ & $\begin{array}{l}N= \\
15667\end{array}$ & $\begin{array}{l}N= \\
17148\end{array}$ & $\begin{array}{l}N= \\
17207\end{array}$ & $\begin{array}{l}N= \\
15010\end{array}$ & $\begin{array}{l}N= \\
10703\end{array}$ & $\begin{array}{l}N= \\
10902\end{array}$ & $\begin{array}{l}N= \\
8130\end{array}$ \\
\hline \multicolumn{9}{|l|}{ Sex: } \\
\hline \multirow[t]{2}{*}{ male } & 7463 & 8246 & 9101 & 9116 & 7822 & 5279 & 5509 & 4276 \\
\hline & $(54 \%)$ & $(53 \%)$ & $(53 \%)$ & $(53 \%)$ & $(52 \%)$ & $(49 \%)$ & $(51 \%)$ & $(53 \%)$ \\
\hline \multirow[t]{2}{*}{ female } & 6491 & 7421 & 8047 & 8091 & 7188 & 5424 & 5393 & 3854 \\
\hline & $(47 \%)$ & $(47 \%)$ & $(47 \%)$ & $(47 \%)$ & $(48 \%)$ & $(51 \%)$ & $(50 \%)$ & $(47 \%)$ \\
\hline \multirow{2}{*}{$\begin{array}{l}\text { Age t0 } \\
\text { (years) }\end{array}$} & 7.14 & 7.24 & 7.12 & 7.18 & 7.39 & 7.73 & 7.78 & 8.02 \\
\hline & $(4.51)$ & $(4.55)$ & $(4.52)$ & $(4.56)$ & $(4.55)$ & $(4.67)$ & $(4.69)$ & $(4.77)$ \\
\hline \multirow[t]{2}{*}{$\Delta$ Age (years) } & 0.48 & 0.48 & 0.48 & 0.47 & 0.46 & 0.46 & 0.45 & 0.49 \\
\hline & $(0.17)$ & $(0.17)$ & $(0.16)$ & $(0.16)$ & $(0.16)$ & $(0.16)$ & $(0.16)$ & $(0.16)$ \\
\hline \multicolumn{9}{|l|}{$\begin{array}{l}\text { Weight group } \\
\text { (t0): }\end{array}$} \\
\hline \multirow[t]{2}{*}{ underweight } & 1371 & 1473 & 1568 & 1613 & 1500 & 1080 & 1105 & 897 \\
\hline & $(10 \%)$ & $(9 \%)$ & $(9 \%)$ & $(9 \%)$ & $(10 \%)$ & $(10 \%)$ & $(10 \%)$ & $(11 \%)$ \\
\hline \multirow{2}{*}{$\begin{array}{l}\text { normal } \\
\text { weight }\end{array}$} & 10053 & 11410 & 12728 & 12782 & 10817 & 7526 & 7593 & 5586 \\
\hline & & $(73 \%)$ & & & & $(70 \%)$ & $(70 \%)$ & $(69 \%)$ \\
\hline \multirow[t]{2}{*}{ overweight } & 1235 & 1430 & 1496 & 1442 & 1394 & 1024 & 1049 & 733 \\
\hline & $(9 \%)$ & $(9 \%)$ & $(9 \%)$ & $(8 \%)$ & $(9 \%)$ & $(10 \%)$ & $(10 \%)$ & $(9 \%)$ \\
\hline \multirow[t]{2}{*}{ obese } & 1295 & 1354 & 1356 & 1370 & 1299 & 1073 & 1155 & 914 \\
\hline & $(9 \%)$ & $(9 \%)$ & $(8 \%)$ & $(8 \%)$ & $(9 \%)$ & & $(11 \%)$ & $(11 \%)$ \\
\hline \multirow[t]{2}{*}{ BMI-SDS t0 } & 0.19 & 0.19 & 0.18 & 0.17 & 0.19 & 0.23 & 0.23 & 0.24 \\
\hline & $(1.19)$ & $(1.18)$ & $(1.15)$ & $(1.16)$ & $(1.19)$ & $(1.24)$ & $(1.24)$ & $(1.28)$ \\
\hline \multirow[t]{2}{*}{ BMI-SDS t1 } & 0.20 & 0.18 & 0.19 & 0.18 & 0.21 & 0.22 & 0.25 & 0.33 \\
\hline & $(1.18)$ & $(1.17)$ & $(1.14)$ & $(1.15)$ & $(1.18)$ & $(1.23)$ & $(1.23)$ & $(1.28)$ \\
\hline \multirow{2}{*}{$\begin{array}{l}\triangle \mathrm{BMI}-\mathrm{SDS} / 3 \\
\text { months }\end{array}$} & 0.01 & 0.00 & 0.01 & 0.01 & 0.02 & 0.00 & 0.01 & 0.06 \\
\hline & $(0.28)$ & $(0.28)$ & $(0.28)$ & $(0.28)$ & $(0.29)$ & $(0.28)$ & $(0.29)$ & $(0.29)$ \\
\hline
\end{tabular}


Overall, there was an increase of $\beta_{5 y}=0.007$ (95\% Cl 0.006 to $\left.0.009 ; p<0.001\right)$ in $\triangle$ BMI-SDS per 5 years between 2005 and 2019, i.e., the mean change rate between t0 and t 1 increased over time. The increase was similar across the age groups but differed significantly across weight groups. Whereas the groups UW, NW, and OW showed marginally significant effects around $\beta_{5 y}=0.005$, a substantially higher effect was present in the OB group ( $\beta_{5 y}=0.014,95 \% \mathrm{Cl} 0.007$ to $\left.0.020 ; p<0.001\right)$. From 2019 to 2020 , we found a mean increase of $\beta=0.046(95 \% \mathrm{Cl} 0.036$ to $0.055 ; p<0.001)$ - more than 30 times higher than the rate before 2020. The increase was higher in younger children (1-to-6-years: $\beta=0.063 ; 95 \% \mathrm{Cl} 0.046$ to 0.079 ; $p<0.001 ; 6$-to-12-years: $\beta=0.048 ; 95 \% \mathrm{Cl} 0.029$ to $0.066 ; p<0.001$ ). In adolescents, the effect did not reach the level of significance. The trends are visualized in Figs. $1 \mathrm{~A}$ and $2 \mathrm{~A}$.

\section{Trends in weight gain and weight loss}

Notably, from 2005 to 2019 , there was a positive trend $\left(\mathrm{OR}_{5 y}=1.05 ; 95 \% \mathrm{Cl} 1.03\right.$ to $\left.1.06 ; \mathrm{p}<0.001\right)$ in the proportion of children with a high positive weight change (weight gain) and a negative one $\left(\mathrm{OR}_{5 y}=0.95\right.$; $95 \% \mathrm{Cl} 0.94$ to $0.96 ; \mathrm{p}<0.001$ ) in the proportion of children with a high negative weight change (weight loss). Whereas we found no difference in the trend between age groups for weight gain, the trend for weight loss was stronger in 6-to-12-years old children $\left(\mathrm{OR}_{5 y}=0.93 ; 95 \% \mathrm{Cl} 0.91\right.$ to $\left.0.96 ; \mathrm{p}<0.001\right)$. Considering the weight status, both effects, weight gain and weight loss, were substantially stronger in the $\mathrm{OB}$ group (weight gain: $\mathrm{OR}_{5 \mathrm{y}}=1.14 ; 95 \% \mathrm{Cl} 1.08$ to $1.20 ; \mathrm{p}<0.001$; weight loss: $\mathrm{OR}_{5 y}=0.85 ; 95 \% \mathrm{Cl}$ 0.81 to $0.89 ; p<0.001)$, which is consistent with the higher increase of $\triangle B M I-S D S$ in this group. For weight gain, the effects in UW, NW, and OW varied between ORs of 1.02 and 1.05, reaching the level for significance only for NW. For weight loss, we found smaller but similar effects for NW $\left(\mathrm{OR}_{5 \mathrm{y}}=0.96,95 \%\right.$ $\mathrm{Cl} 0.94$ to $0.97 ; \mathrm{p}<0.001)$ and $\mathrm{OW}\left(\mathrm{OR}_{5 y}=0.95 ; 95 \% \mathrm{Cl} 0.91\right.$ to $\left.0.99 ; \mathrm{p}=0.032\right)$.

From 2019 to 2020, the increase in the proportion of children gaining weight corresponds to an OR of 1.37 (95\% Cl 1.28 to $1.46 ; \mathrm{p}<0.001)$. As for $\triangle \mathrm{BMI}$-SDS, the effects are more than 30 times as high as for the years before. A similar effect was observed for the proportion of children losing weight $(O R=0.716$; $95 \% \mathrm{Cl} 0.668$ to $0.767 ; \mathrm{p}<0.001)$. Both effects were stronger for higher weight status. Hence, the highest effects were found in the $\mathrm{OB}$ group. Here, the $\mathrm{OR}$ for a high positive weight change was $\mathrm{OR}_{\text {high_pos }}=1.90$ $(95 \% \mathrm{Cl} 1.47$ to $2.44 ; \mathrm{p}<0.001)$ and for a high negative weight change was $\mathrm{OR}_{\text {high_neg }}=0.55(95 \% \mathrm{Cl} 0.43$ to $0.71 ; p<0.001)$. For $O W$, the respective effects were $O R_{\text {high_pos }}=1.70(95 \% \mathrm{Cl} 1.30$ to $2.24 ; \mathrm{p}<0.001)$ and $\mathrm{OR}_{\text {high_neg }}=0.64(95 \% \mathrm{Cl} 0.49$ to $0.84 ; \mathrm{p}<0.001)$, and for $\mathrm{NW}$, OR $\mathrm{R}_{\text {high_pos }}=1.31 ; 95 \% \mathrm{Cl} 1.19$ to $1.44 ; \mathrm{p}<$ $0.001)$ and $O R_{\text {high_neg }}=0.75(95 \% \mathrm{Cl} 0.68$ to $0.83 ; p<0.001)$. No significant effects were found for UW. Considering age, the effects were more pronounced in children and younger adolescents (1-to-6-years: $\mathrm{OR}_{\text {high_pos }}=1.36 ; 95 \% \mathrm{Cl} 1.21$ to $1.53 ; \mathrm{p}<0.001 \& \mathrm{OR}_{\text {high_neg }}=0.68 ; 95 \% \mathrm{Cl} 0.60$ to $0.77 ; \mathrm{p}<0.001 ; 6$-to-12years: $\mathrm{OR}_{\text {high_pos }}=1.54 ; 95 \% \mathrm{Cl} 1.35$ to $1.77 ; \mathrm{p}<0.001 \& \mathrm{OR}_{\text {high_neg }}=0.64 ; 95 \% \mathrm{Cl} 0.55$ to $\left.0.74 ; \mathrm{p}<0.001\right)$. In adolescents, only the effect for a high positive change reached the level of statistical significance $\left(O R_{\text {high_pos }}=1.19 ; 95 \% \mathrm{Cl} 1.02\right.$ to $1.39 ; \mathrm{p}=0.023$ ). All effects (overall as well as stratified by age and weight group) are summarized in Table 2 and visualized in Figs. $1 \mathrm{~B} / \mathrm{C}$ and $2 \mathrm{~B} / \mathrm{C}$. For the interest of the 
reader, the prevalences of $\mathrm{UW}, \mathrm{NW}, \mathrm{OW}$, and $\mathrm{OB}$ are given stratified by age and weight group in Supplementary Table 3 in the Online-Only Supplements. 
Table 2

Overview of the effects for trends between 2005 and 2019 and between 2019 and 2020 .

$\triangle \mathrm{BMI}-\mathrm{SDS}$

proportion high positive

proportion high negative

effects 2005-

2019

$\begin{array}{lllllll}\text { per } 5 \text { years } & \beta(95 \% \mathrm{Cl}) & \begin{array}{l}\mathrm{P}- \\ \text { value }\end{array} & \text { OR }(95 \% \mathrm{Cl}) & \begin{array}{l}\mathrm{P}- \\ \text { value }\end{array} & \text { OR }(95 \% \mathrm{Cl}) & \begin{array}{l}\mathrm{P} \text { - } \\ \text { value }\end{array} \\ \text { overall } & 0.007 & \mathrm{p}< & 1.045 & \mathrm{p}< & 0.948 & \mathrm{p}< \\ & {[0.006,0.009]} & 0.001 & {[1.033,1.057]} & 0.001 & {[0.937,0.959]} & 0.001\end{array}$

Per age group

$1-6$ years

0.008

$[0.006,0.011]$

$\mathrm{p}<\quad 1.041$

0.001

$[1.021,1.060]$

$\mathrm{p}<\quad 0.969$

$[0.951,0.987]$

$\mathrm{p}<$

$6-12$ years

0.007

$\mathrm{p}<\quad 1.073$

$[0.004,0.010]$

0.001

$[1.048,1.099]$

$\mathrm{p}<$

0.934

0.001

$[0.913,0.956]$

$\mathrm{p}<$

$12-18$ years

0.005

$[0.001,0.009]$

$\mathrm{p}=\quad 1.051$

$0.005 \quad[1.019,1.085]$

$\mathrm{p}<$

0.961

0.001

$[0.931,0.992]$

$\mathrm{p}=$

Per weight

group

underweight

0.005

$[-0.001,0.011]$

$\mathrm{p}=\quad 1.024$

1.024
$[0.980,1.071]$

$p=$
0.638

0.992

$\mathrm{p}=$

normal weight

$\begin{array}{ll}0.006 & p< \\ {[0.004,0.009]} & 0.001\end{array}$

1.046

[1.030,1.063]

$\mathrm{p}<$
0.001

[0.944,1.043]

0.999

overweight

0.005

$[-0.001,0.011]$

$\mathrm{p}=\quad 1.034$

0.117

[0.984,1.086]

$\mathrm{p}=\quad 0.954$

0.957

[0.942,0.972]

$\mathrm{p}<$

0.014
$[0.007,0.020]$

obese

$\mathrm{p}<$
0.001

[1.077,1.202]

0.370

$[0.913,0.997]$

$\mathrm{p}=$

0.031

effects 2019-

2020

overall

0.046

$[0.036,0.055]$

$\mathrm{p}<\quad 1.367$

0.001

[1.280,1.459]

$\mathrm{p}<\quad 0.849$

0.001

[0.810,0.890]

$p<$
0.001

Per age group

$1-6$ years

0.063

[0.046,0.079]

$\mathrm{p}<\quad 1.358$

0.001

$[1.207,1.527]$

$\mathrm{p}<$

$\mathrm{p}<$

0.001

0.716

$[0.668,0.767]$

$\mathrm{p}<$

0.001

6-12 years

0.048

$[0.029,0.066]$

$\mathrm{p}<\quad 1.544$

0.001

[1.350,1.767]

$\mathrm{p}<$

0.001

0.680

$[0.602,0.769]$

$p<$

12-18 years

$\begin{array}{ll}0.015 & p= \\ {[-0.007,0.037]} & 0.344\end{array}$

1.190

[1.017,1.394]

$\mathrm{p}=$
0.023

0.638

$[0.552,0.736]$

$\mathrm{p}<$

0.001 


\begin{tabular}{|c|c|c|c|c|c|c|}
\hline \multicolumn{7}{|l|}{$\begin{array}{l}\text { Per weight } \\
\text { group }\end{array}$} \\
\hline underweight & $\begin{array}{l}0.031 \\
{[-0.002,0.064]}\end{array}$ & $\begin{array}{l}\mathrm{p}= \\
0.085\end{array}$ & $\begin{array}{l}1.121 \\
{[0.876,1.435]}\end{array}$ & $\begin{array}{l}p= \\
0.756\end{array}$ & $\begin{array}{l}0.805 \\
{[0.609,1.064]}\end{array}$ & $\begin{array}{l}p= \\
0.214\end{array}$ \\
\hline normal weight & $\begin{array}{l}0.045 \\
{[0.032,0.058]}\end{array}$ & $\begin{array}{l}p< \\
0.001\end{array}$ & $\begin{array}{l}1.308 \\
{[1.189,1.439]}\end{array}$ & $\begin{array}{l}p< \\
0.001\end{array}$ & $\begin{array}{l}0.749 \\
{[0.678,0.826]}\end{array}$ & $\begin{array}{l}\mathrm{p}< \\
0.001\end{array}$ \\
\hline overweight & $\begin{array}{l}0.054 \\
{[0.018,0.089]}\end{array}$ & $\begin{array}{l}p< \\
0.001\end{array}$ & $\begin{array}{l}1.707 \\
{[1.301,2.238]}\end{array}$ & $\begin{array}{l}p< \\
0.001\end{array}$ & $\begin{array}{l}0.639 \\
{[0.489,0.836]}\end{array}$ & $\begin{array}{l}p< \\
0.001\end{array}$ \\
\hline obese & $\begin{array}{l}0.046 \\
{[0.013,0.078]}\end{array}$ & $\begin{array}{l}p= \\
0.001\end{array}$ & $\begin{array}{l}1.896 \\
{[1.474,2.439]}\end{array}$ & $\begin{array}{l}\mathrm{p}< \\
0.001\end{array}$ & $\begin{array}{l}0.551 \\
{[0.426,0.714]}\end{array}$ & $\begin{array}{l}\mathrm{p}< \\
0.001\end{array}$ \\
\hline
\end{tabular}

\section{Discussion}

This registry-based study found a small but stable positive trend in $\triangle B M I-S D S$ between 2005 and 2020, with an exceptional aggravation during the last year - the latter most likely attributable to COVID-19induced measures. Our findings of positive trends in $\triangle B M I-S D S$ between 2005 and 2019 is not contrary to studies reporting stabilizing or even downward trends of overweight and obesity prevalence. ${ }^{26,27}$ Rather, we found the most pronounced dynamics within the already affected population. In general, this trend was positive for all age groups and strongest in overweight and obese children. Even if some subgroup effects did not reach the significance level, this stable consistency is alarming: especially in obese children, we would expect some negative effects because of the statistical regression to the mean phenomenon. I.e., if we observe some extreme values (like BMI-SDS values in the range of obesity), we would expect a future point being less extreme and, therefore, nearer to the mean. The aggravation of childhood obesity becomes even more evident when we look at the proportions of children who lose or gain some weight. Between 2005 and 2008, the percentage of children losing some weight varied between $45 \%$ and $50 \%$ in the OW and OB weight group and decreased to around $40 \%$ in 2019 . On the other hand, there was an increase of overweight and obese children gaining even more weight: from about 26\%(OW)/22\%(OB) between 2005 and 2008 to 29\%(OW)/28\%(OB) in 2019 (pre-pandemic).

The effects from 2019 to 2020 are even more alarming. During the first few months of the pandemic, the proportions of children losing weight shrunk by more than $10 \%$ and reached $33 \%$ and $26 \%$ in the OW and OB weight group, respectively. At the same time, the proportions of children gaining weight rose by more than $10-41 \%(\mathrm{OW})$ and $42 \%(\mathrm{OB})$, which is consistent with the higher pandemic $\triangle B M I-S D S$ values. These are tremendously high effects for a time interval of a few months, surmounting the cumulative effects of the 15 years before. Even though adolescents seem to be less severely affected, there is no reason for giving the all-clear: the obesity prevalence in this age group increased from 2005 to 2020 (pre-pandemic) from 10-19\% (Supplementary Table 3 in the Online-Only Supplements). Older adolescents are the age 
group with the highest obesity prevalence. Here, it becomes evident that even a small increase can have large effects over time. The same effects were found in normalweight children but less pronounced. The already most affected population seems to be the most vulnerable, whether in terms of small long-term or short-term effects.

Our findings are in line with several studies on COVID-19-related weight changes in adults ${ }^{9,10}$ and studies on weight gain in children associated with the economic crisis in $2007-2008^{17,18,28}$ or the great Fukushima earthquake 2011. ${ }^{19,29}$ Zheng et al. showed that the initial increase of BMI and obesity prevalence persisted or even aggravated at least two years after the earthquake. The effect was more pronounced if children also experienced a personal disaster like a stay in an evacuation center or the death of a family member. ${ }^{29}$ Indeed, a Korean study in 226 pediatric patients of a growth clinic found a mean BMI-SDS change of +0.2 SDS after the lockdown accompanied by higher LDL, triglyceride, uric acid, and total cholesterol values. ${ }^{30}$

Although we have no information on the health-related behavior regarding our study population, a decrease in PA and an unfavorable change in dietary behavior seem to be the most likely explanation for the sudden and high change in weight trends. Germany was mildly to moderately affected during the first COVID-19 wave. However, in late March 2020, non-essential educational, cultural, and administrative facilities were closed. Only essential shops stayed open. Playgrounds and sports facilities were closed and cordoned off. Schools and nurseries stayed entirely closed until mid-May. Education was only possible through online platforms. From mid-May, a partial re-opening was allowed with restrictions (hygiene rules, distancing, wearing masks, strict separation of groups, etc. had to be secured). Most schools implemented a hybrid model of online and on-site lessons. The proportion of on-site classes was often less than $50 \%$. Besides, compulsory education was suspended until the end of the school year, i.e., parents could decide whether or not a child had to go to school. Nurseries were also re-opened in midMay, but opening hours were often limited due to staff shortages (employees belonged to a risk group, childcare obligations, COVID-19-related quarantine). ${ }^{31}$ Children and adolescents were living through a time of rapid changes in their daily routines. For many, the days became less structured, which is known to increases the risk of obesogenic behaviors. ${ }^{32,33}$ And indeed, several studies showed an accelerated weight gain during the summer months compared to the school year and time in nurseries ${ }^{33,34}$ with higher effects in overweight than in normal weight children. ${ }^{35}$ The mechanisms are not fully understood. ${ }^{33}$ A COVID-19-related decrease in PA has already been shown, ${ }^{5-8,36-38}$ often related to an increase of SB. 5,7,8,37,38 There are mixed results concerning dietary behavior. ${ }^{5,38,39}$ Two studies reported higher consumption of fruits or vegetables, ${ }^{5,39}$ one lower. ${ }^{38}$ There was also an increase in the consumption of unhealthy foods and sweets. ${ }^{5,39}$ The latter might be tightly connected to increased snacking during the increased screen time ${ }^{4,40}$ or due to boredom. ${ }^{39}$ This is in line with studies in adults, reporting an increase in food consumption because of increased snacking, due to boredom, and due to the increased availability of food during the COVID-induced confinement. ${ }^{9,41}$

\section{Limitations}

Page $12 / 20$ 
The participation in the CrescNet registry is voluntary. We have no information of non-participants, neither of the number of non-participants nor the reasons on non-participation.

\section{Conclusion}

We found a small but stable positive trend in mean $\triangle B M I-S D S$ and in the proportion of children gaining weight between 2005 and 2020 . These trends were accompanied by a decrease in the proportion of children losing weight, both adding to the still-growing problem of childhood obesity. During the COVID-19 pandemic, these effects have increased by more than 30 times within the relatively short period. We hypothesize that these effects are caused by the COVID-19-induced changes in health-related behavior and may lead to a significant further aggravation of the childhood obesity pandemic.

\section{Declarations}

\section{Acknowledgements}

We thank all participating pediatricians, their patients, and the patients' families. This work was supported by the Free State of Saxony as per the budget approved by the state parliament and the German Research Foundation (DFG) for the Collaborative Research Center "Obesity Mechanisms" CRC1052 (No 209933838), project C05. The CrescNet registry infrastructure was supported by grants from Hexal AG Germany, NovoNordisk Pharma GmbH, Merck Serono Pharma GmbH, Lilly Deutschland $\mathrm{GmbH}$, Pfizer Pharma GmbH and Ipsen Pharma GmbH; ClinicalTrials.gov NCT03072537).

\section{Conflict of Interest}

The authors declare no conflict of interest. The funders had no role in the design of the study; in the collection, analyses, or interpretation of data; in the writing of the manuscript, or in the decision to publish the results.

\section{Authors contributions}

$\mathrm{RP}, \mathrm{RG}$, and WK devised the project and the main conceptual ideas. MV and MG drafted the work and analyzed and interpreted the data and designed the figures; MV, WK, and TP discussed and finalized the first draft of the manuscript; all authors revised the work critically for important intellectual content and discussed the results; $\mathrm{EK}, \mathrm{RG}, \mathrm{CM}, \mathrm{CB}$, and RP contributed to the conception and design of data collection; $\mathrm{CM}$ and $\mathrm{CB}$ designed and maintain the software used for data collection and data management; $\mathrm{RG}, \mathrm{CB}$, and RP are responsible for data collection and data quality; all authors approved the final version of the manuscript.

\section{References}


1. McElroy E, Patalay P, Moltrecht B, et al. Demographic and health factors associated with pandemic anxiety in the context of COVID-19. Br J Health Psychol 2020;25(4):934-44.

2. Loades ME, Chatburn E, Higson-Sweeney N, et al. Rapid systematic review: The impact of social isolation and loneliness on the mental health of children and adolescents in the context of COVID-19. J Am Acad Child Adolesc Psychiatry 2020;59(11):1218-39.

3. Workman J. How Much May COVID-19 School Closures Increase Childhood Obesity? Obesity (Silver Spring) 2020;28(10):1787.

4. Jia P. A changed research landscape of youth's obesogenic behaviours and environments in the post-COVID-19 era. Obesity Reviews [Internet] 2020 [cited 2020 Dec 2];online ahead of print. Available from: https://onlinelibrary.wiley.com/doi/abs/10.1111/obr.13162

5. Pietrobelli A, Pecoraro L, Ferruzzi A, et al. Effects of COVID-19 Lockdown on Lifestyle Behaviors in Children with Obesity Living in Verona, Italy: A Longitudinal Study. Obesity (Silver Spring) 2020;10.1002/oby.22861.

6. Ruíz-Roso MB, de Carvalho Padilha P, Matilla-Escalante DC, et al. Changes of Physical Activity and Ultra-Processed Food Consumption in Adolescents from Different Countries during Covid-19 Pandemic: An Observational Study. Nutrients 2020;12(8):2289.

7. Dunton GF, Do B, Wang SD. Early effects of the COVID-19 pandemic on physical activity and sedentary behavior in children living in the U.S. BMC Public Health 2020;20(1):1351.

8. Xiang M, Zhang Z, Kuwahara K. Impact of COVID-19 pandemic on children and adolescents' lifestyle behavior larger than expected. Prog Cardiovasc Dis 2020;63(4):531-2.

9. Zachary Z, Brianna F, Brianna L, et al. Self-quarantine and weight gain related risk factors during the COVID-19 pandemic. Obes Res Clin Pract 2020;14(3):210-6.

10. He M, Xian Y, Lv X, He J, Ren Y. Changes in Body Weight, Physical Activity, and Lifestyle During the Semi-lockdown Period After the Outbreak of COVID-19 in China: An Online Survey. Disaster Med Public Health Prep [Internet] 2020 [cited 2020 Nov 19];online ahead of print. Available from:

https://www.ncbi.nlm.nih.gov/pmc/articles/PMC7385320/

11. Geserick M, Vogel M, Gausche R, et al. Acceleration of BMI in Early Childhood and Risk of Sustained Obesity. N Engl J Med 2018;379(14):1303-12.

12. Cuschieri S, Grech S. COVID-19: a one-way ticket to a global childhood obesity crisis? J Diabetes Metab Disord 2020;1-4.

13. Nogueira-de-Almeida CA, Del Ciampo LA, Ferraz IS, Del Ciampo IRL, Contini AA, Ued F da V. COVID19 and obesity in childhood and adolescence: a clinical review. J Pediatr (Rio J) 2020;96(5):546-58. 
14. Malhotra S, Sivasubramanian R, Singhal V. Adult obesity and its complications: a pediatric disease? Curr Opin Endocrinol Diabetes Obes 2021;28(1):46-54.

15. Fernandes DM, Oliveira CR, Guerguis S, et al. Severe Acute Respiratory Syndrome Coronavirus 2 Clinical Syndromes and Predictors of Disease Severity in Hospitalized Children and Youth. J Pediatr [Internet] 2020 [cited 2021 Jan 2];online ahead of print. Available from:

https://www.ncbi.nlm.nih.gov/pmc/articles/PMC7666535/

16. An R. Projecting the impact of the coronavirus disease-2019 pandemic on childhood obesity in the United States: A microsimulation model. J Sport Health Sci 2020;9(4):302-12.

17. Ueda P, Kondo N, Fujiwara T. The global economic crisis, household income and pre-adolescent overweight and underweight: a nationwide birth cohort study in Japan. Int $\mathrm{J}$ Obes (Lond) 2015;39(9):1414-20.

18. Rajmil L, Medina-Bustos A, Fernández de Sanmamed M-J, Mompart-Penina A. Impact of the economic crisis on children's health in Catalonia: a before-after approach. BMJ Open 2013;3(8):e003286.

19. Zheng $\mathrm{W}$, Yokomichi $\mathrm{H}$, Matsubara $\mathrm{H}$, et al. Longitudinal changes in body mass index of children affected by the Great East Japan Earthquake. Int J Obes (Lond) 2017;41(4):606-12.

20. Agarwal DV, Sunitha BK. COVID - 19: Current Pandemic and Its Societal Impact. Int J Adv Sci 2020;29(5s):432-9.

21. Kiess W, Gausche R, Keller A, Burmeister J, Willgerodt H, Keller E. Computer-guided, populationbased screening system for growth disorders (CrescNet) and on-line generation of normative data for growth and development. Horm Res 2001;56 Suppl 1:59-66.

22. Wabitsch M, Moss A. [Evidence-based (S3) guideline of the Working Group on Childhood and Adolescent Obesity (AGA) of the German Obesity Society (DAG) and the German Society of Pediatrics and Adolescent Medicine (DGKJ)] [Internet]. 2019;Available from: https://www.awmf.org/leitlinien/detail/II/050-002.html

23. Kromeyer-Hauschild K, Wabitsch M, Kunze D, et al. Percentiles of body mass index in children and adolescents evaluated from different regional German studies. Monatsschrift fur Kinderheilkunde 2001;149(8):807-18.

24. Bretz F, Hothorn T, Westfall P. Multiple Comparisons Using R. 1st edition. Boca Raton, FL: Chapman and Hall/CRC; 2010.

25. R Core Team. R: A language and environment for statistical computing [Internet]. Vienna, Austria: 2020. Available from: https://www.R-project.org/ 
26. Garrido-Miguel M, Cavero-Redondo I, Álvarez-Bueno C, et al. Prevalence and Trends of Overweight and Obesity in European Children From 1999 to 2016. JAMA Pediatr 2019;173(10):e192430.

27. Kess A, Spielau U, Beger C, et al. Further Stabilization and Even Decrease in the Prevalence Rates of Overweight and Obesity in German Children and Adolescents from 2005 to 2015: A Cross-Sectional and Trend Analysis. Public Health Nutr 2017;20(17):3075-83.

28. Norte A, Sospedra I, Ortíz-Moncada R. Influence of economic crisis on dietary quality and obesity rates. Int J Food Sci Nutr 2019;70(2):232-9.

29. Yokomichi $\mathrm{H}$, Zheng $\mathrm{W}$, Matsubara $\mathrm{H}$, et al. Impact of the great east Japan earthquake on the body mass index of preschool children: a nationwide nursery school survey. BMJ Open 2016;6(4):e010978.

30. Kang HM, Jeong DC, Suh BK, Ahn MB. The Impact of the Coronavirus Disease-2019 Pandemic on Childhood Obesity and Vitamin D Status. J Korean Med Sci 2021;36(3):e21.

31. Freestate of Saxony. [Archive of expired official announcements] [Internet]. [cited 2021 Jan 1];Available from: https://www.coronavirus.sachsen.de/archiv-der-abgelaufenen-amtlichenbekanntmachungen-7295.html

32. Brazendale K, Beets MW, Weaver RG, et al. Understanding differences between summer vs. school obesogenic behaviors of children: the structured days hypothesis. Int J Behav Nutr Phys Act 2017;14(1):100.

33. von Hippel PT, Workman J. From Kindergarten Through Second Grade, U.S. Children's Obesity Prevalence Grows Only During Summer Vacations. Obesity (Silver Spring) 2016;24(11):2296-300.

34. Moreno JP, Johnston CA, Chen T-A, et al. Seasonal variability in weight change during elementary school. Obesity (Silver Spring) 2015;23(2):422-8.

35. Hippel P von, Powell B, Downey D, Rowland N. The effect of school on overweight in childhood: gain in body mass index during the school year and during summer vacation. Am J Public Health 2007;97(4):696-702.

36. Tison GH, Avram R, Kuhar P, et al. Worldwide Effect of COVID-19 on Physical Activity: A Descriptive Study. Ann Intern Med 2020;173(9):767-70.

37. Moore SA, Faulkner G, Rhodes RE, et al. Impact of the COVID-19 virus outbreak on movement and play behaviours of Canadian children and youth: a national survey. Int J Behav Nutr Phys Act 2020;17(1):85.

38. López-Bueno R, López-Sánchez GF, Casajús JA, et al. Health-Related Behaviors Among School-Aged Children and Adolescents During the Spanish Covid-19 Confinement. Front Pediatr 2020;8:573. 
39. Ruiz-Roso MB, de Carvalho Padilha P, Mantilla-Escalante DC, et al. Covid-19 Confinement and Changes of Adolescent's Dietary Trends in Italy, Spain, Chile, Colombia and Brazil. Nutrients 2020;12(6):1807.

40. Nagata JM, Abdel Magid HS, Pettee Gabriel K. Screen Time for Children and Adolescents During the Coronavirus Disease 2019 Pandemic. Obesity (Silver Spring) 2020;28(9):1582-3.

41. Ammar A, Brach M, Trabelsi K, et al. Effects of COVID-19 Home Confinement on Eating Behaviour and Physical Activity: Results of the ECLB-COVID19 International Online Survey. Nutrients 2020;12(6):1583.

\section{Figures}




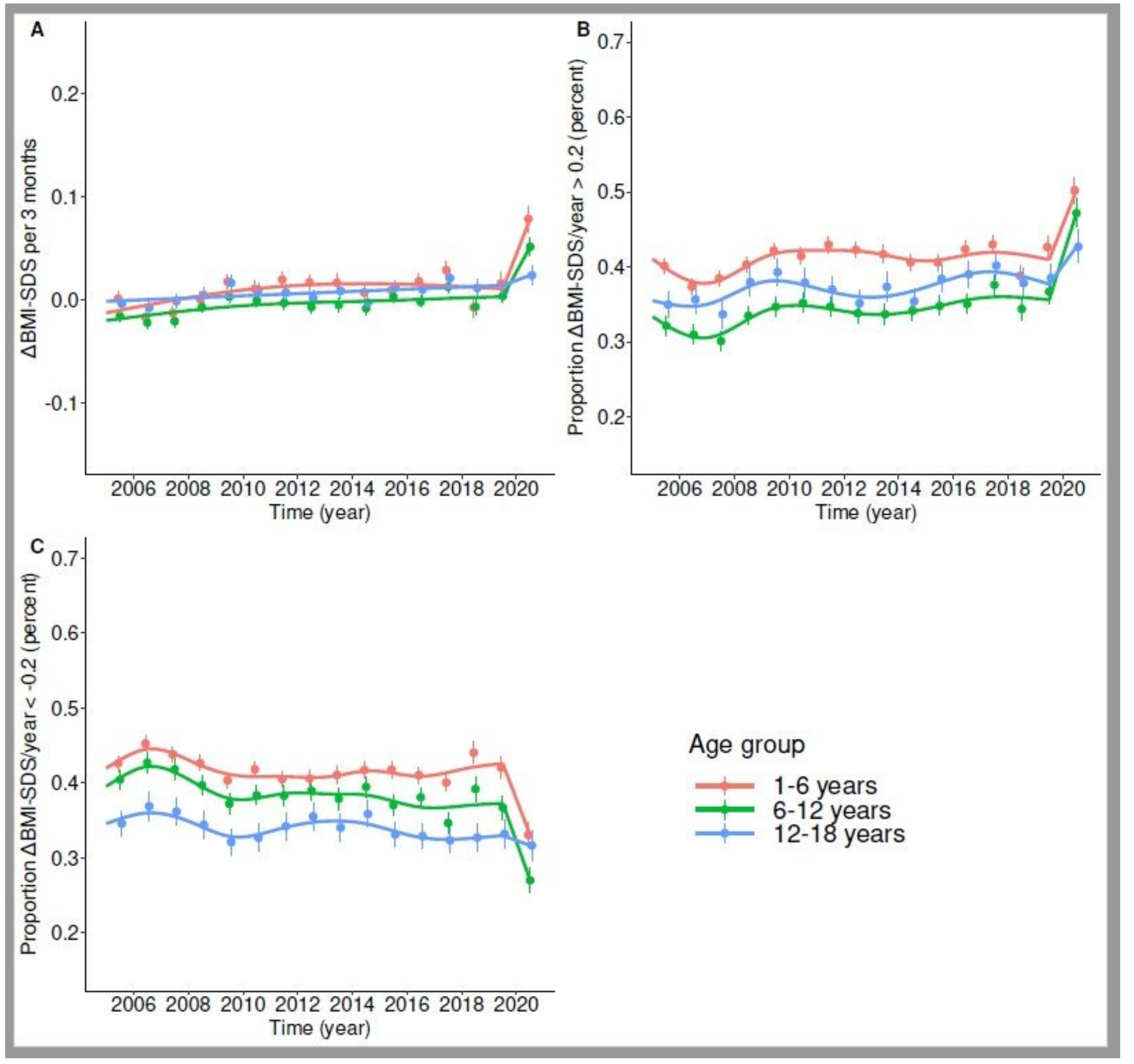

\section{Figure 1}

Trends in $\triangle B M I-S D S(A)$ and in the proportions of children gaining (B)/losing (C) weight between 2005 and 2020 stratified by age group. Trends between 2005 and 2019 were modeled via linear additive mixed models (lines). In addition, yearly means $\pm 95 \%$-confidence levels (points and whiskers) are given. The trends were mainly stable between 2005 and 2019 (pre-pandemic). There is a substantial increase in $\triangle \mathrm{BMI}-\mathrm{SDS}$ and in the proportions of children gaining weight between 2019 (pre-pandemic) and 2020 (after the onset of anti-pandemic measures), especially in the younger age groups. Likewise, the proportions of children losing weight decreased substantially between 2019 (pre-pandemic) and 2020. 


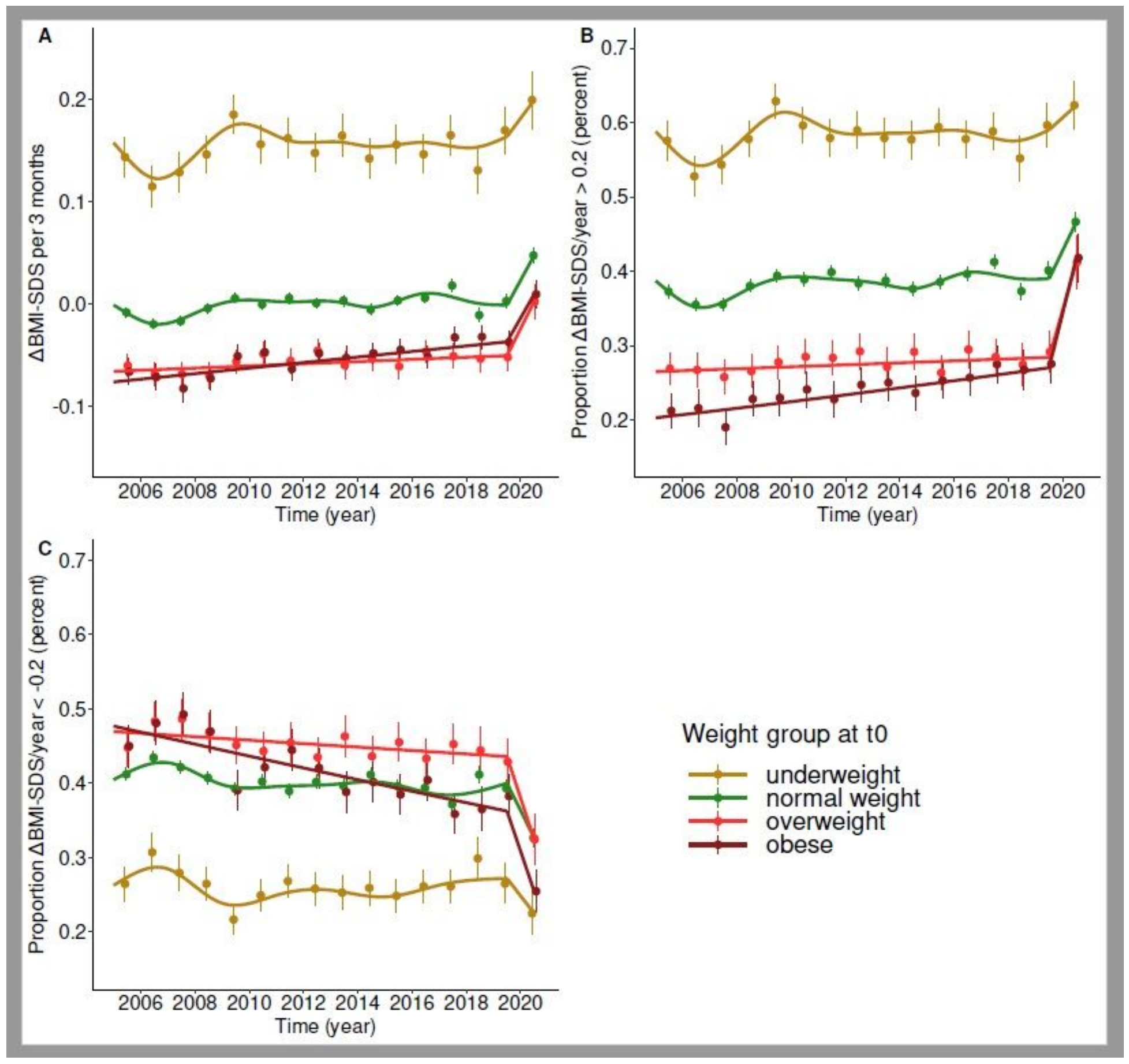

Figure 2

Trends in $\triangle B M I-S D S(A)$ and in the proportions of children gaining (B)/losing (C) weight between 2005 and 2020 stratified by weight group. Trends between 2005 and 2019 were modeled via linear additive mixed models (lines). In addition, yearly means $\pm 95 \%$-confidence levels (points and whiskers) are given. The trends were mainly stable between 2005 and 2019 (pre-pandemic). However, we found an increase in $\triangle \mathrm{BMI}-S D S$ and in the proportions of children gaining weight and a decrease in proportions of children losing weight between 2005 and 2019, especially in the weight groups overweight and obese. From 2019 (pre-pandemic) to 2020 (after the onset of anti-pandemic measures), the effects increased more than 30 times. 


\section{Supplementary Files}

This is a list of supplementary files associated with this preprint. Click to download.

- 202102supplementarymaterial.pdf 